\title{
Effect of BML-111 on the intestinal mucosal barrier in sepsis and its mechanism of action
}

\author{
HUAIZHENG LIU, ZUOLIANG LIU, SHANGPING ZHAO, CHUANZHENG SUN and MINGSHI YANG \\ Emergency and Intensive Care Center, The Third Xiangya Hospital of Central South University, \\ Changsha, Hunan 410013, P.R. China
}

Received July 18, 2014; Accepted March 26, 2015

DOI: $10.3892 / \mathrm{mmr} .2015 .3746$

\begin{abstract}
S),6(R)-7-trihydroxymethyl heptanoate(BML-111) is an lipoxin A4 receptor agonist, which modulates the immune response and attenuates hemorrhagic shock-induced acute lung injury. However, the role of BML-111 in sepsis and in the intestinal mucosal barrier are not well understood. Therefore, the present study was designed to investigate the effect of BML-111 on the intestinal mucosal barrier in a rat model of sepsis. Furthermore, the molecular mechanism of action of BML-111 was evaluated. The cecal ligation and puncture-induced rat model of sepsis was constructed, and BML-111 was administered at three different doses. The results revealed that BML-111 suppressed the elevation of the pro-inflammatory cytokines tumor necrosis factor- $\alpha$ and interleukin-6, while enhancing the elevation of the anti-inflammatory cytokine transforming growth factor- $\beta$ in the intestine. In addition, BML-111 significantly upregulated rat defensin-5 mRNA expression levels and downregulated the induction of cell apoptosis as well as caspase-3 activity in the intestine. All these results demonstrated that BML-111 exerted protective effects on the intestinal mucosal barrier in sepsis. Further, it was indicated that alterations in the expression of toll-like receptor (TLR)2 and TLR4 may be one of the molecular mechanisms underlying the protective effect of BML-111. The present study therefore suggested that BML-111 may be a novel therapeutic agent for sepsis.
\end{abstract}

\section{Introduction}

Sepsis is the leading cause of mortality in intensive care units; it affects millions of people worldwide and over one in four patients with sepsis succumbs to it $(1,2)$.

Correspondence to: Professor Mingshi Yang, Emergency and Intensive Care Center, The Third Xiangya Hospital of Central South University, 138 Tongzipo Road, Changsha, Hunan 410013, P.R. China

E-mail: mingshiyang666@163.com

Key words: BML-111, sepsis, intestinal mucosal barrier, toll-like receptors
The intestinal tract is the largest bacterial storage pool in the body; it contains endogenous and exogenous microorganisms, which are susceptive to ischemia-reperfusion injuries due to sepsis (3). The mucosal epithelium forms an intestinal mucosal barrier between the body and the environment of the lumen, and the intestinal mucosal barrier has an important role in the defense against microbial pathogens. However, adverse conditions may lead to intestinal mucosal barrier dysfunction, allowing the normal intestinal microbiota to cross this mucosal barrier into the body and to infect other organs (4-6), which may promote multiple organ dysfunction and failure $(7,8)$.

5(S),6(R)-7-trihydroxymethyl heptanoate (BML-111), a lipoxin (LX)A4 receptor agonist, is a synthetic analogue of LXA4. BML-111 has a higher biological stability than LXA4 and exhibits greater anti-inflammatory activity than native LXA4 $(9,10)$. Several studies have shown that BML-111 modulates the immune response and reduces the severity of arthritis (11) and acute pancreatitis (12). In addition, BML-111 attenuates hemorrhagic shock-induced acute lung injury $(13,14)$ and exerts protective effects against acetaminophen-induced acute liver injury (15). However, the effect of BML-111 in sepsis and on the intestinal mucosal barrier has remained to be fully elucidated. Therefore, the present study was designed to investigate the effect of BML-111 on the intestinal mucosal barrier in a rat modelof sepsis. Furthermore, the molecular mechanism of action of BML-111 was investigated.

\section{Materials and methods}

Sepsis model. The present study was approved by the Institutional Animal Care and Use Committee of Central South University (Changsha, China) and performed in accordance with the Guide for the Care and Use of Laboratory Animals published by the National Institutes of Health (publication no. 86-23, revised 1986). 150 male Sprague-Dawley (SD) rats weighing 250-300 g were provided by the Experimental Animal Center of The Third Xiangya Hospital of the Central South University (Changsha, China). The SD rats were randomly divided into three groups: Sham group $(n=30)$, sepsis group $(n=30)$ and treatment group $(n=90)$. The treatment group was sub-divided into groups of 0.5 , 1 and $2 \mathrm{mg} / \mathrm{kg}$ according to the treatment dose of BML-111. Sepsis was induced by cecal ligation and puncture (CLP) as 
described previously $(16,17)$. Briefly, under anesthesia using intraperitoneal injection of sodium pentobarbital $(45 \mathrm{mg} / \mathrm{kg}$; Merck, Darmstadt, Germany), a midline abdominal incision was performed. The cecum was exteriorized and ligated below the ileocecal valve. Then the cecum was punctured twice at various sites with an 18-gauge needle and gently compressed until a small amount of stool was extruded. The cecum was replaced in the abdomen, and the abdominal incision was closed in layers. Rats in the sham group underwent the same procedure without the CLP. After surgery, the rats were injected subcutaneously with saline $(5 \mathrm{ml} / 100 \mathrm{~g}$ body weight/day) (16). A 5-cm segment of the ileum was excised at $6,12,24$ and $48 \mathrm{~h}$ following CLP and stored at $-80^{\circ} \mathrm{C}$ or fixed in $10 \%$ paraformaldehyde (Xinchenghuagong, Inc., Guangzhou, China).

BML-111 administration. BML-111 was obtained from Calbiochem (San Diego, CA, USA) and dissolved in sterile saline. Rats received intraperitoneal injections of BML-111 or an equivalent volume of saline at 12 and $1 \mathrm{~h}$ prior to CLP surgery.

Reverse transcription quantitative polymerase chain reaction ( $R T-q P C R)$. Primers for rat defensin (RD)-5 and $\beta$-actin were obtained from Sangon Biotech Company (Shanghai, China) with sequences as follows: RD-5 forward, 5'-ATCGGTGGCCTCAGAACTC-3' and reverse, 5'-TCGCAGCCATTGAAGAAATT-3'; and $\beta$-actin forward, 5'-AGCCATGTACGTAGCCATCC-3' and reverse, 5'-CTCTCAGCTGTGGTGGTAA-3'. Total RNA was extracted using TRIzol (Invitrogen Life Technologies, Carlsbad, CA, USA). Subsequently, cDNA from the total RNA was synthesized by using the RevertAid ${ }^{\mathrm{TM}}$ First Strand cDNA Synthesis kit (Fermentas, Vilnius, Lithuania). The quantitative PCR reactions were performed using a SYBR Green PCR kit (Applied Biosystems, Life Technologies, Thermo Fisher Scientific, Waltham, MA, USA) in an ABIPRISM7900 system (Applied Biosystems). Briefly, for the qPCR, $2 \mu \mathrm{l} \mathrm{cDNA}$, $300 \mathrm{nM}$ primers and SYBR Green (Applied Biosystems) were mixed to obtain a final volume of $20 \mu \mathrm{l}$. The reaction conditions were as follows: 40 cycles at $95^{\circ} \mathrm{C}$ for $30 \mathrm{sec}, 58^{\circ} \mathrm{C}$ for $30 \mathrm{sec}$ and $72^{\circ} \mathrm{C}$ for $30 \mathrm{sec}$. Amplification of the expected single products was confirmed by dynamic melting curves and by electrophoresis on $2 \%$ agarose gels (Amresco, Solon, $\mathrm{OH}$, USA). Fluorescence data were automatically collected and analyzed by SDS software (version 2.2; Applied Biosystems) using $\mathrm{Ct}$ values and the relative quantification of gene products was normalized against the housekeeping gene $\beta$ actin.

Cytokine measurement. Transforming growth factor beta 1 (TGF- $\beta 1$ ), interleukin (IL)-6 and tumour necrosis factor- $\alpha$ (TNF- $\alpha$ ) ELISA kits were purchased from eBioscience (San Diego, CA, USA). The levels of TNF- $\alpha$, TGF- $\beta 1$ and IL- 6 in the intestine were measured using these commercially available ELISA kits following the manufacturer's instructions.

Terminal deoxynucleotidyl transferase dUTP nick end labeling (TUNEL). The TUNEL assay was performed to determine the number of apoptotic cells in the intestine. Tissues were fixed in $10 \%$ paraformaldehyde for $24 \mathrm{~h}$ and embedded in paraffin.
Then the paraffin-embedded tissue was cut into 5- $\mu \mathrm{m}$ sections and placed on glass slides. TUNEL staining was performed using a TUNEL Apoptosis Assay kit (Beyotime Institute of Biotechnology, Shanghai, China) according to the manufacturer's instructions. The apoptotic cells displayed brown staining within the nucleus. The number of apoptotic cells were counted throughout five lesion regions at random under an optical microscope (Olympus CX31; Olympus, Tokyo, Japan).

Western blot analysis. Tissue samples were homogenized with a Dounce glass homogenizer (Thomas Scientific, Swedesboro, NJ, USA) using radioimmunoprecipitation lysis buffer (50 mmol/1 Tris ( $\mathrm{pH} 7.4$ ), $150 \mathrm{mmol} / 1 \mathrm{NaCl}, 1 \%$ Triton $\mathrm{X}-100,0.5 \%$ sodium deoxycholate, $0.1 \%$ SDS, $1 \%$ Nonidet $\mathrm{P}-40,1 \mathrm{mmol} / 1$ sodium orthovanadate, $1 \mathrm{mmol} / 1$ EDTA and $100 \mathrm{mg} / \mathrm{ml}$ phenylmethanesulfonylfluoride). Lysates were centrifuged at $4^{\circ} \mathrm{C}$ for $15 \mathrm{~min}$ at $10,000 \mathrm{xg}$, and the supernatants were collected. Protein samples were separated using 10\% SDS-PAGE. After electrophoresis, the proteins were transferred to polyvinylidene difluoride membranes (Bio-Rad Laboratories, Inc., Hercules, CA, USA) and blocked with $5 \%$ nonfat milk powder. The membranes were incubated with antibodies to toll-like receptor (TLR)2 (rabbit polyclonal; cat. no. SC-10739; Santa Cruz Biotechnology, Inc., Dallas, TX, USA; 1:400), TLR4 (rabbit polyclonal; cat. no. SC-30002; Santa Cruz Biotechnology, Inc.; 1:400) and $\beta$ actin (rabbit polyclonal; cat. no. SC-130657; Santa Cruz Biotechnology, Inc.) at $4{ }^{\circ} \mathrm{C}$ overnight, followed by incubation with the secondary antibody (goat anti rabbit IgG; cat. no. BV-S8008; Biovol Biotech, Shanghai, China) at $37^{\circ} \mathrm{C}$ for $1 \mathrm{~h}$. The signals was detected using an enhanced chemilluminescence western blotting substrate kit (Pierce, Rockford, IL, USA).

Caspase-3 activity assay. The caspase-3 activity in the intestine was measured using a caspase- 3 colorimetric assay kit purchased from Beyotime Institute of Biotechnology. All procedures were performed according to the manufacturer's instructions.

Statistical analysis. All values are expressed as the mean \pm standard deviation and are representative of at least three independent experiments. Statistical significance was evaluated by Student's $t$ test for comparisons between two groups using SPSS 19.0 statistical software (IBM corp., Armonk, NY, USA). $\mathrm{P}<0.05$ was considered to indicate a statistically significant difference between values.

\section{Results}

Effect of BML-111 on cytokine expression in the intestine following CLP-induced sepsis. Compared with the sham group, the expression levels of the cytokines TNF- $\alpha$, IL-6 and TGF- $\beta 1$ in the intestine were significantly elevated in the sepsis group at each time-point following CLP $(\mathrm{P}<0.01)$ (Fig. 1). IL-6 was significantly decreased in rats treated with BML-111 at 1 and $2 \mathrm{mg} / \mathrm{kg}$ compared with the rats in the sepsis group $(\mathrm{P}<0.01)$. Septic rats treated with $0.5 \mathrm{mg} / \mathrm{kg}$ BML-111 showed significantly decreased IL-6 levels at 12 and $48 \mathrm{~h}(\mathrm{P}<0.05)$, but not at $6 \mathrm{~h}(\mathrm{P}>0.05)$, compared with those in the septic rats 

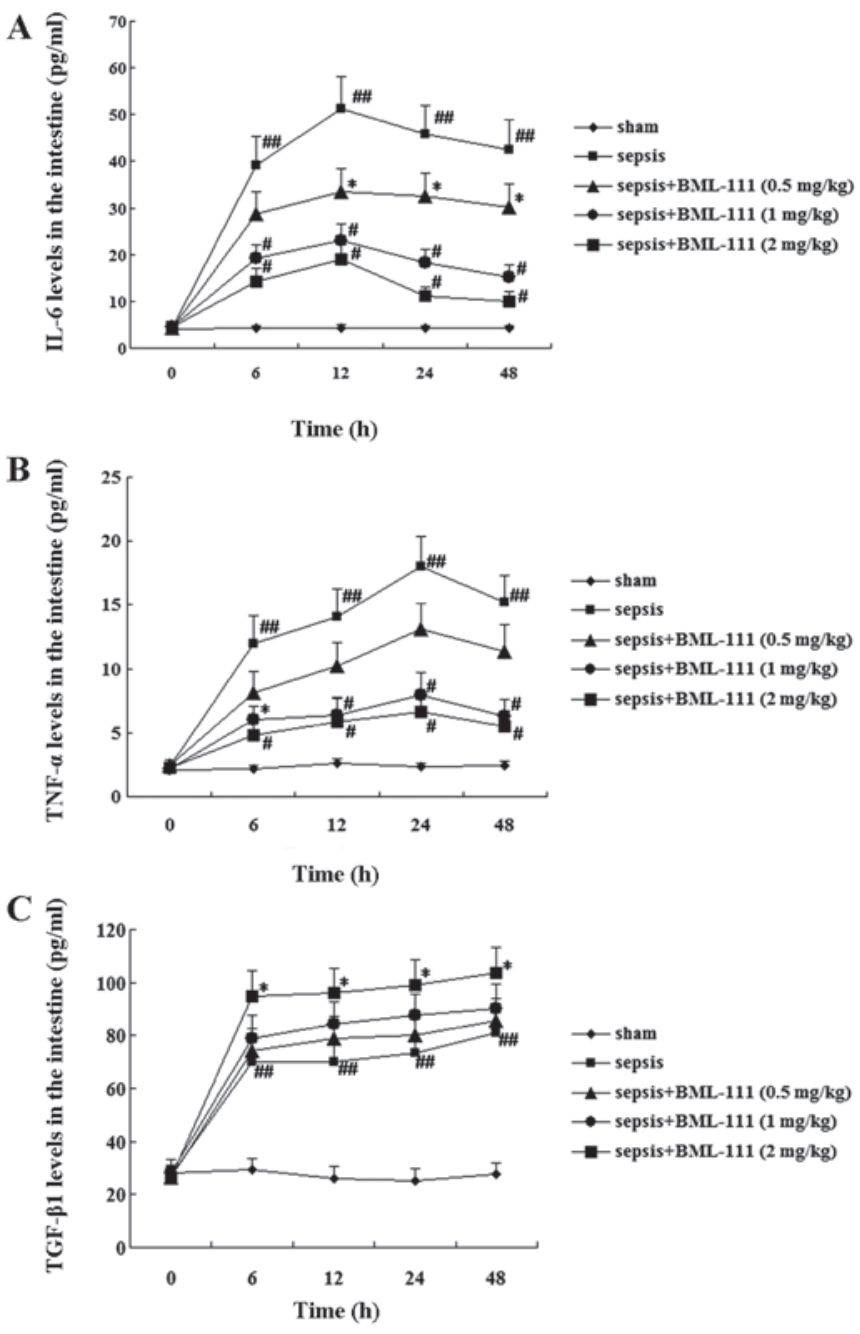

Figure 1. Effect of BML-111 on cytokine expression in the intestine following CLP-induced sepsis. (A) IL-6 levels in the intestine. (B) TNF- $\alpha$ levels in the intestine. (C) TGF- $\beta 1$ levels in the intestine. The data are expressed as the mean \pm standard deviation ${ }^{(\# \#} \mathrm{P}<0.01$ compared with the sham group, ${ }^{*} \mathrm{P}<0.05$ and ${ }^{\#} \mathrm{P}<0.01$ compared with the sepsis group). TNF, tumor necrosis factor; IL, interleukin; TGF, transforming growth factor.

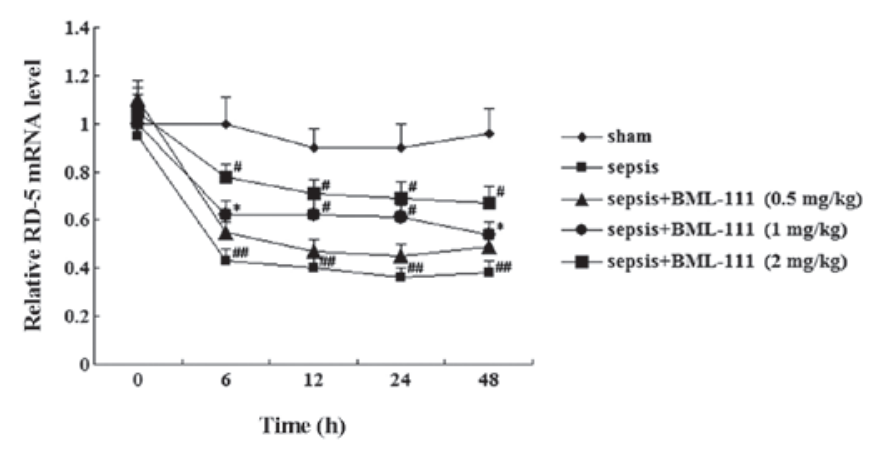

Figure 2. Effect of BML-111 on RD-5 mRNA expression in the intestine following cecal ligation and puncture-induced sepsis. The data are expressed as the mean \pm standard deviation ${ }^{\# \#} \mathrm{P}<0.01$ compared with the sham group, ${ }^{*} \mathrm{P}<0.05$ and ${ }^{\#} \mathrm{P}<0.01$ compared with the sepsis group). RD-5, rat defensin 5 .

without treatment (Fig. 1A). 1 and $2 \mathrm{mg} / \mathrm{kg} \mathrm{BML-111} \mathrm{attenu-}$ ated CLP-induced TNF- $\alpha$ elevation in the intestine; however, $0.5 \mathrm{mg} / \mathrm{kg}$ BML-111 did not show any effects to CLP-induced TNF- $\alpha$ elevation at each time-point following CLP $(\mathrm{P}>0.05)$
(Fig. 1B). Compared with the sepsis group, $2 \mathrm{mg} / \mathrm{kg}$ BML-111 increased TGF- $\beta 1$ levels from 6 to $48 \mathrm{~h}(\mathrm{P}<0.05)$; however, neither 0.5 nor $1 \mathrm{mg} / \mathrm{kg}$ BML-111 significantly influenced TGF- $\beta 1$ levels at each time-point following CLP $(\mathrm{P}>0.05)$ (Fig. 1C).

Effect of BML-111 on RD-5 mRNA expression in the intestine following CLP-induced sepsis. RT-qPCR revealed that the relative mRNA levels of RD-5 in the intestine were significantly decreased at 6-48 $\mathrm{h}$ following CLP in all groups except the sham group $(\mathrm{P}<0.01) .1$ and $2 \mathrm{mg} / \mathrm{kg}$ BML-111 significantly elevated RD-5 mRNA at each time-point following CLP. A slight but not significant increase in RD-5 mRNA was observed in septic rats treated with $0.5 \mathrm{mg} / \mathrm{kg}$ BML-111 (P>0.05) (Fig. 2).

Effect of BML-111 on cell apoptosis and caspase-3 activity in the intestine following CLP-induced sepsis. The TUNEL assay revealed that CLP increased the apoptotic rate of cells in the intestine, with the most prominent increase found at $48 \mathrm{~h}$ following CLP $(\mathrm{P}<0.01) .2 \mathrm{mg} / \mathrm{kg}$ BML-111 significantly decreased CLP-induced apoptosis from 6 to $48 \mathrm{~h}(\mathrm{P}<0.05)$. $1 \mathrm{mg} / \mathrm{kg}$ BML-111 significantly decreased CLP-induced apoptosis at 24 and $48 \mathrm{~h}(\mathrm{P}<0.05)$, but not at 6 and $12 \mathrm{~h}$ $(\mathrm{P}>0.05)$. However, apoptotic rates in the intestine of septic rats were not significantly altered following treatment with $0.5 \mathrm{mg} / \mathrm{kg} \mathrm{BML-111} \mathrm{(P>0.05)} \mathrm{(Fig.} \mathrm{3A} \mathrm{and} \mathrm{B).}$

Compared with the sham group, caspase-3 activity in the intestine was also increased at each time-point following CLP $(\mathrm{P}<0.01)$. 1 and $2 \mathrm{mg} / \mathrm{kg}$ BML-111 significantly upregulated caspase- 3 activity at each time-point following CLP. However, compared with the septic rats, no significant alteration of caspase-3 activity was observed in septic rats treated with $0.5 \mathrm{mg} / \mathrm{kg} \mathrm{BML-111} \mathrm{(P>0.05)} \mathrm{(Fig.} \mathrm{3C).}$

Effect of BML-111 on TLR2 and TLR4 expression in the intestine following CLP-induced sepsis. Western blot analysis was used to examine the alteration of TLR2 and TLR4 expression in the intestine. The expression levels of TLR2 and TLR4 protein were significantly increased following CLP, while 1 and $2 \mathrm{mg} / \mathrm{kg}$ BML-111 significantly decreased the expression of TLR2 and TLR4 compared with that in the sepsis group. $0.5 \mathrm{mg} / \mathrm{kg}$ BML-111 also decreased the expression levels of TLR4 protein; however, $0.5 \mathrm{mg} / \mathrm{kg}$ BML-111 did not affect TLR2 expression (Fig. 4, and Table I).

\section{Discussion}

In the present study, BML-111 was administered at three different doses in a rat model of sepsis and the results revealed that BML-111 exerted its effect in a dose-dependent manner. High doses of BML-111 showed beneficial effects on the intestinal mucosal barrier at each time-point following CLP, while the effect of low and medium doses of BML-111 on the intestinal mucosal barrier depended on the time following CLP.

Cytokines are important pleiotropic regulators of the immune response, which have a crucial role in the pathogenesis of sepsis. TNF- $\alpha$ and IL- 6 are proinflammatory cytokines, and the elevation of TNF- $\alpha$ and IL- 6 was suggested 
A
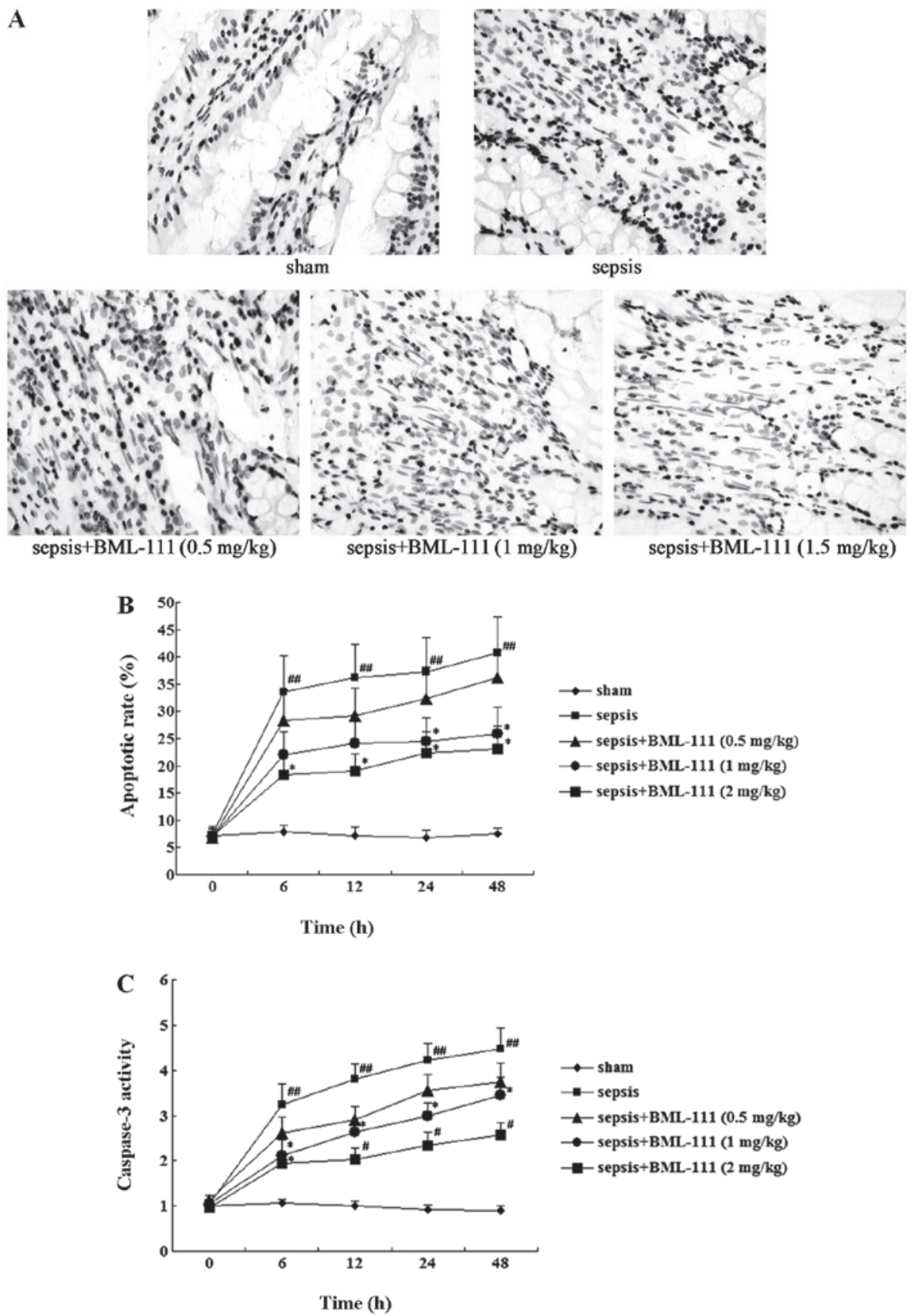

Figure 3. Effect of BML-111 on cell apoptosis and caspase-3 activity in the intestine following CLP-induced sepsis. (A) TUNEL staining of the intestine $48 \mathrm{~h}$ following CLP. TUNEL-positive cells displayed brown staining within the nucleus (magnification, $\mathrm{x} 400$ ). (B) Cell apoptosis rates in the intestine. (C) Caspase- 3 activity in the intestine. The data are expressed as the mean \pm standard deviation ${ }^{* \#} \mathrm{P}<0.01$ compared with the sham group, ${ }^{*} \mathrm{P}<0.05$ and ${ }^{\#} \mathrm{P}<0.01$ compared with the sepsis group). CLP, cecal ligation and puncture; TUNEL, terminal deoxynucleotidyl transferase dUTP nick end labeling.

to be correlated with poor outcome in patients with severe sepsis and septic shock (18). TGF- $\beta$ is an anti-inflammatory cytokine. Compared to healthy controls, patients with sepsis were shown to have elevated levels of TGF- $\beta$ (19). Consistent with these previous studies, the results of the present study indicated that the pro-inflammatory cytokines and the anti-inflammatory cytokine were increased in the intestine following CLP-induced sepsis. BML-111 showed different effects to pro-inflammatory and anti-inflammatory cytokines, as it suppressed the elevation of the pro-inflammatory cytokines TNF- $\alpha$ and IL- 6 , while it enhanced the elevation of anti-inflammatory cytokine TGF- $\beta$ in the intestine. It was previously reported that IL- 6 and TNF- $\alpha$ had adverse effects on intestinal mucosa $(20-22)$. Treatment with TGF- $\beta$ was shown to improve survival of patients with septic shock (23) and contribute to the protection of the intestinal barrier (24). Therefore, the results of the present study indicated that BML-111 may exert beneficial and protective effects on the intestinal mucosal barrier.

RD-5 is a native immune substance, which belongs to the rat $\alpha$-defensin gene family. RD-5 expression is restricted to the small intestine and in situ hybridization experiments indicated that it is specifically localized to the Paneth cells in the intestinal crypt (24). RD-5 has a key role in intestinal mucosal barrier function $(25,26)$. It was implicated that RD-5 reduction results in an increase in the number of bacteria 
Table I. Relative protein levels of TLR2 and TLR4 in the intestine of rats with sepsis following treatment with BML-111.

\begin{tabular}{|c|c|c|c|c|c|}
\hline Group & $0 \mathrm{~h}$ & $6 \mathrm{~h}$ & $12 \mathrm{~h}$ & $24 \mathrm{~h}$ & $48 \mathrm{~h}$ \\
\hline \multicolumn{6}{|l|}{ TLR2 } \\
\hline Sham & $0.31 \pm 0.04$ & $0.3 \pm 0.04$ & $0.35 \pm 0.05$ & $0.31 \pm 0.04$ & $0.32 \pm 0.05$ \\
\hline Sepsis & $0.34 \pm 0.04$ & $0.76 \pm 0.09^{a}$ & $0.77 \pm 0.11^{\mathrm{a}}$ & $0.81 \pm 0.11^{\mathrm{a}}$ & $0.88 \pm 0.08^{\mathrm{a}}$ \\
\hline $\begin{array}{l}\text { Sepsis+BML-111 } \\
(0.5 \mathrm{mg} / \mathrm{kg})\end{array}$ & $0.32 \pm 0.06$ & $0.68 \pm 0.07$ & $0.70 \pm 0.10$ & $0.74 \pm 0.13$ & $0.77 \pm 0.13$ \\
\hline $\begin{array}{l}\text { Sepsis+BML-111 } \\
(1 \mathrm{mg} / \mathrm{kg})\end{array}$ & $0.31 \pm 0.05$ & $0.55 \pm 0.05^{\mathrm{b}}$ & $0.57 \pm 0.06^{\mathrm{b}}$ & $0.61 \pm 0.05^{\mathrm{b}}$ & $0.68 \pm 0.07^{b}$ \\
\hline $\begin{array}{l}\text { Sepsis+BML-111 } \\
(2 \mathrm{mg} / \mathrm{kg})\end{array}$ & $0.32 \pm 0.04$ & $0.52 \pm 0.06^{\mathrm{b}}$ & $0.53 \pm 0.07^{b}$ & $0.59 \pm 0.05^{\mathrm{b}}$ & $0.63 \pm 0.07^{b}$ \\
\hline \multicolumn{6}{|l|}{ TLR4 } \\
\hline Sham & $0.18 \pm 0.03$ & $0.17 \pm 0.04$ & $0.18 \pm 0.04$ & $0.19 \pm 0.03$ & $0.21 \pm 0.05$ \\
\hline Sepsis & $0.2 \pm 0.04$ & $0.84 \pm 0.10^{\mathrm{a}}$ & $0.86 \pm 0.09^{a}$ & $0.91 \pm 0.11^{\mathrm{a}}$ & $0.93 \pm 0.09^{\mathrm{a}}$ \\
\hline $\begin{array}{l}\text { Sepsis+BML-111 } \\
(0.5 \mathrm{mg} / \mathrm{kg})\end{array}$ & $0.19 \pm 0.05$ & $0.55 \pm 0.06^{\mathrm{b}}$ & $0.60 \pm 0.06^{\mathrm{b}}$ & $0.64 \pm 0.05^{\mathrm{b}}$ & $0.7 \pm 0.08^{\mathrm{b}}$ \\
\hline $\begin{array}{l}\text { Sepsis+BML-111 } \\
(1 \mathrm{mg} / \mathrm{kg})\end{array}$ & $0.18 \pm 0.04$ & $0.5 \pm 0.07^{c}$ & $0.56 \pm 0.07^{\mathrm{b}}$ & $0.61 \pm 0.07^{\mathrm{b}}$ & $0.63 \pm 0.08^{b}$ \\
\hline $\begin{array}{l}\text { Sepsis+BML-111 } \\
(2 \mathrm{mg} / \mathrm{kg})\end{array}$ & $0.22 \pm 0.03$ & $0.44 \pm 0.06^{\mathrm{c}}$ & $0.46 \pm 0.06^{c}$ & $0.51 \pm 0.06^{\mathrm{c}}$ & $0.55 \pm 0.09^{c}$ \\
\hline
\end{tabular}

Values are expressed as the mean \pm standard deviation of three independent experiments. $\beta$-actin was used as a loading control. ${ }^{a} \mathrm{P}<0.01$, compared with the sham group. ${ }^{b} \mathrm{P}<0.05$, compared with the sepsis group. ${ }^{\mathrm{c}} \mathrm{P}<0.01$, compared with the sepsis group. TLR, toll-like receptor.



Figure 4. Representative western blots of TLR2 and TLR4 protein in the intestine of rats with sepsis following treatment with BML-111. $\beta$-actin was used as a loading control. TLR, toll-like receptor.

existing in the enteric cavity (27). In the present study, RD-5 mRNA was reduced following CLP-induced sepsis; however, 1 and $2 \mathrm{mg} / \mathrm{kg}$ BML-111 significantly upregulated RD-5 mRNA expression levels in rats with sepsis. These results demonstrated that BML-111 exerted protective effects on the intestinal mucosal barrier function.

The mucosal epithelium is renewed every 3 to 5 days and homeostasis is maintained by balancing intestinal proliferation with cell apoptosis (28). Several studies have shown that in sepsis, intestinal proliferation and apoptosis are markedly perturbed $(29,30)$. Caspase-3 is activated by various apoptosis-stimulating factors and is then able to induce apoptosis via acting on other members of the caspase family (31). A TUNEL assay and caspase- 3 activity assay were used in the present study to evaluate intestinal mucosal apoptosis. Sepsis increased the apoptotic rate and caspase- 3 activity in the intestine; however, BML-111 was able to downregulate the induction of the apoptotic rate and caspase-3 activity of septic rats to exert its protective effect.

Furthermore, the present study examined the molecular mechanism of action of BML-111. TLRs have central roles in the mammalian innate immune system, as they control multiple dendritic cell functions and detect microbial pathogens (32). Activation of TLR signaling leads to induction of multiple steps in the inflammatory reactions, contributing to the elimination of invading pathogens and initiation of anti-microbial host defense response (33). TLR2 and TLR4 are important members of the TLR signaling pathway and recognize a large number of microbial member components (34). TLR2 and TLR4 signaling is achieved by recruiting members of the myeloid differentiation factor 88 (MyD88) pathway through MyD88 adapter-like/toll-interleukin 1 receptor domain containing adaptor protein, leading to the activation of nuclear factor- $\kappa \mathrm{B}$, mitogen-activated protein 
kinase and interferon, which are important for inflammatory cytokine expression. In the present study, the expression of TLR2 and TLR4 was examined in the intestine. The expression of TLR2 and TLR4 was decreased in the BML-111 group compared with that in the sepsis group. These results indicated that TLR2 and TLR4 alteration may be one of the molecular mechanisms underlying the protective effect of BML-111.

In conclusion, in a rat model of sepsis, BML-111 suppressed the elevation of the pro-inflammatory cytokines TNF- $\alpha$ and IL-6, while it enhanced the elevation of anti-inflammatory cytokine TGF- $\beta$ in the intestine. In addition, BML-111 significantly upregulated RD-5 mRNA expression levels and downregulated the induction of the cell apoptosis rate and caspase- 3 activity in the intestine. All these results demonstrated that BML-111 exerts protective effects on the intestinal mucosal barrier in sepsis. The underlying molecular mechanisms of this protective role may in part be attributable to its suppression of TLR2 and TLR4 by BML-111. The present study suggested that BML-111 may be a novel therapeutic agent for sepsis.

\section{References}

1. Martin GS: The future is bright. Crit Care Med 34: 2484-2485, 2006.

2. Dellinger RP, Levy MM, Carlet JM, et al: Surviving Sepsis Campaign: International guidelines for management of severe sepsis and septic shock: 2008. Crit Care Med 36: 296-327, 2008.

3. Kanwar S, Windsor AC, Welsh F, Barclay GR, Guillou PJ and Reynolds JV: Lack of correlation between failure of gut barrier function and septic complications after major upper gastrointestinal surgery. Ann Surg 231: 88-95, 2000.

4. Berg RD and Garllington AW: Translocation of certain indigenous bacteria from the gastrointestinal tract to the mesenteric lymph nodes and other organs in a gnotobiotic mouse model. Infect Immun 23: 403-411, 1979.

5. Deckx RJ, Vantrappen GR and Parein MM: Localization of lysozyme activity in Paneth cell granule fraction. Biochim Biophys Acta 139: 204-207, 1967.

6. Deitch EA, Maejima K and Berg R: Effect of oral antibiotics and bacterial overgrowth on the translocation of the GI tract microflora in burned rats. J Trauma 25: 385-392, 1985.

7. Suliburk J, Helmer K, Moore F and Mercer D: The gut in systemic inflammatory response syndrome and sepsis. Enzyme systems fighting multiple organ failure. Eur Surg Res 40: 184-189, 2008.

8. Zasloff M: Antimicrobial peptides of multicellular organisms. Nature 415: 389-395, 2002.

9. Serhan CN, Maddox JF, Petasis NA, et al: Design of lipoxin A4 stable analogs that block transmigration and adhesion of human neutrophils. Biochemistry 34: 14609-14615, 1995.

10. Lee TH, Lympany P, Crea AE and Spur BW: Inhibition of leukotriene B4-induced neutrophil migration by lipoxin A4: structure-function relationships. Biochem Biophys Res Commun 180: 1416-1421, 1991.

11. Zhang L, Zhang X, Wu P, et al: BML-111, a lipoxin receptor agonist, modulates the immune response and reduces the severity of collagen-induced arthritis. Inflamm Res 57: 157-162, 2008.

12. Wang YZ, Zhang YC, Cheng JS, et al: BML-111, a lipoxin receptor agonist, ameliorates 'two-hit'-induced acute pancreatitis-associated lung injury in mice by the upregulation of heme oxygenase-1. Artif Cells Nanomed Biotechnol 42: 110-120, 2014.
13. Li HB, Wang GZ, Gong J, et al: BML-111 attenuates hemorrhagic shock-induced acute lung injury through inhibiting activation of mitogen-activated protein kinase pathway in rats. J Surg Res 183: 710-719, 2013.

14. Gong J, Li HB, Guo S, Shang Y and Yao SL: Lipoxin receptor agonist, may be a potential treatment for hemorrhagic shock-induced acute lung injury. Med Hypotheses 79: 92-94, 2012.

15. El-Agamy DS, Makled MN and Gamil NM: Protective effects of ML-111 against acetaminophen-induced acute liver injury in mice. J Physiol Biochem 70: 141-149, 2014.

16. Parker SJ and Watkins PE: Experimental models of gram-negative sepsis. Br J Surg 88: 22-30, 2001.

17. Doi K, Leelahavanichkul A, Yuen PS and Star RA: Animal models of sepsis and sepsis-induced kidney injury. J Clin Invest 119: 2868-2878, 2009.

18. Damas P, Ledoux D, Nys M, Vrindts Y, De Groote D, Franchimont $\mathrm{P}$ and Lamy M: Cytokine serum level during severe sepsis in human IL-6 as a marker of severity. Ann Surg 215: 356-362, 1992.

19. Marie C, Cavaillon JM and Losser MR: Elevated levels of circulating transforming growth factor-beta 1 in patients with the sepsis syndrome. Ann Intern Med 125: 520-521, 1996.

20. Yang R, Han X, Uchiyama T, Watkins SK, Yaguchi A, Delude RL and Fink MP: IL-6 is essential for development of gut barrier dysfunction after hemorrhagic shock and resuscitation in mice. Am J Physiol Gastrointest Liver Physiol 285: G621-G629, 2003.

21. Wang Q, Fang $\mathrm{CH}$ and Hasselgren PO: Intestinal permeability is reduced and IL-10 levels are increased in septic IL-6 knockout mice. Am J Physiol Regul Integr Comp Physiol 281: R1013-R1023, 2001.

22. Spies M, Chappell VL, Dasu MR, Herndon DN, Thompson JC and Wolf SE: Role of TNF-alpha in gut mucosal changes after severe burn. Am J Physiol Gastrointest Liver Physiol 283: G703-G708, 2002.

23. Perrella MA, Hsieh CM, Lee WS, et al: Arrest of endotoxininduced hypotension by transforming growth factor betal. Proc Natl Acad Sci USA 93: 2054-2059, 1996.

24. Islam MS, Kusakabe M, Horiguchi K, et al: PDGF and TGF- $\beta$ promote tenascin-C expression in subepithelial myofibroblasts and contribute to intestinal mucosal protection in mice. $\mathrm{Br} \mathrm{J}$ Pharmacol 171: 375-388, 2014.

25. Condon MR, Viera A, D'Alessio M and Diamond G: Induction of a rat enteric defensin gene by hemorrhagic shock. Infect Immun 67: 4787-4793, 1999.

26. Bastian A and Schafer H: Human alpha-defensin 1 (HNP-1) inhibits adenoviral infection in vitro. Regul Pept 101: 157-161, 2001.

27. Wilson CL, Ouellette AJ, Satchell DP, et al: Regulation of intestinal alpha-defensin activation by the metalloproteinase matrilysin in innate host defense. Science 286: 113-117, 1999.

28. Hall PA, Coates PJ, Ansari B and Hopwood D: Regulation of cell number in the mammalian gastrointestinal tract: the importance of apoptosis. J Cell Sci 107: 3569-3577, 1994.

29. Coopersmith CM, Stromberg PE, Davis CG, et al: Sepsis from Pseudomonas aeruginosa pneumonia decreases intestinal proliferation and induces gut epithelial cell cycle arrest. Crit Care Med 31: 1630-1637, 2003.

30. Potoka DA, Upperman JS, Zhang XR, et al: Peroxynitrite inhibits enterocyte proliferation and modulates Src kinase activity in vitro. Am J Physiol Gastrointest Liver Physiol 285: G861-G869, 2003.

31. Mishima S, Yukioka T, Matsuda H and Shimazaki S: Mild hypotension and body burns synergistically increase bacterial translocation in rats consistent with a 'two-hit phenomenon'. J Burn Care Rehabil 18: 22-26, 1997.

32. Akira S, Uematsu S and Takeuchi O: Pathogen recognition and innate immunity. Cell 124: 783-801, 2006.

33. Iwasaki A and Medzhitov R: Toll-like receptor control of the adaptive immune responses. Nat Immunol 5: 987-995, 2004.

34. Blasius AL and Beutler B: Intracellular toll-like receptors. Immunity 32: 305-315, 2010. 